\title{
APRENDIZAGEM COOPERATIVA NO ENSINO SUPERIOR: RELATO DE UMA EXPERIÊNCIA
}

\author{
APRENDIZAJE COOPERATIVO EN LA EDUCACIÓN SUPERIOR: INFORME DE \\ UNA EXPERIENCIA
}

\author{
COOPERATIVE LEARNING IN HIGHER EDUCATION: REPORT OF AN \\ EXPERIENCE
}

\author{
Vera Lúcia Messias Fialho CAPELLINI ${ }^{1}$ \\ Marcia Miranda Silveira BELLO ${ }^{2}$ \\ Verônica Lima dos REIS ${ }^{3}$
}

RESUMO: A Aprendizagem Cooperativa (AC) trata-se de uma metodologia de ensino e aprendizagem que visa superar a tradicional por meio de atividades cooperativas; ainda pouco adotada no ensino superior, pressupõe a formação de grupos heterogêneos. Este manuscrito objetiva relatar a experiência vivenciada na disciplina "Prática de Ensino na Educação Infantil" de uma turma de licenciatura em Pedagogia utilizando a metodologia de AC. Participaram 35 alunos(as) da Universidade Estadual Paulista "Júlio de Mesquita Filho" UNESP matriculados no $2^{\circ}$ ano. Os procedimentos demandaram: alinhamento quanto à $\mathrm{AC}$; formação e auto nomeação das equipes de trabalho; criação de $b \log$ e $\log o$; definição de rotina das aulas; avaliação formativa. Foi disponibilizado a cada equipe de trabalho um notebook. As atividades desenvolvidas por meio da AC promoveram: a) formação docente conforme preconizada nas Diretrizes Curriculares Nacionais para a formação inicial em nível superior (Resolução $n^{\circ}$ 02/2015); b) utilização de inovações tecnológicas; c) articulação junto aos coordenadores para que todas as Licenciaturas oferecidas na UNESP atendessem às Diretrizes Curriculares Complementares para a Formação de Docentes para a Educação Básica nos Cursos de Graduação de Pedagogia, Normal Superior e Licenciaturas (Deliberação CEE $\mathrm{n}^{\circ}$ 154/2017). Consideram-se que a AC contribuiu para a formação de todos os atores envolvidos por meio de ações pedagógicas participativas, colaborativas e solidárias - perspectiva inclusiva -, preparando-os para os desafios que se apresentam no campo educacional.

PALAVRAS-CHAVE: Ensino superior. Pedagogia. Aprendizagem cooperativa.

RESUMEN: El aprendizaje cooperativo (AC) es una metodología de enseñanza y aprendizaje que tiene como objetivo superar lo tradicional a través de actividades cooperativas; aún poco adoptado en la educación superior, presupone la formación de

\footnotetext{
${ }^{1}$ Universidade Estadual Paulista (UNESP), Bauru - SP - Brasil. Docente do Departamento de Educação, PósGraduação em Psicologia do Desenvolvimento e Aprendizagem, Pós-Graduação em Docência para a Educação Básica, Faculdade de Ciências. Doutora em Educação Especial (UFSCAR). ORCID: http://orcid.org/0000-00026238-8624. E-mail: vera.capellini@unesp.br

${ }^{2}$ Faculdade Aldete Maria Alves (FAMA), Iturama - MG - Brasil. Docente do Departamento de Educação. ORCID: https://orcid.org/0000-0001-5136-1947. E-mail: marciamsbello@gmail.com

${ }^{3}$ Universidade Estadual Paulista (UNESP), Bauru - SP - Brasil. Pós-Doutoranda - bolsista CAPES - PósGraduação em Psicologia do Desenvolvimento e Aprendizagem, Faculdade de Ciências. ORCID: https://orcid.org/0000-0003-0681-0015.E-mail: veronica.reis@unesp.br
} 
grupos heterogéneos. Este manuscrito tiene como objetivo informar la experiencia vivida en la disciplina "Práctica de enseñanza en educación de la primera infancia" de una clase de pregrado de pedagogía utilizando la metodología de AC. Participaron 35 estudiantes de la Universidad Estatal de São Paulo "Júlio de Mesquita Filho" - UNESP matriculados en el $2^{\circ}$ año. Los procedimientos requeridos: alineación AC; capacitación y auto cita de equipos de trabajo; blog y creación de logotipos; definición rutinaria de clases; evaluación formativa. Cada equipo de trabajo recibió un cuaderno. Las actividades desarrolladas a través de la AC promovieron: a) la formación del profesorado como se recomienda en las Directrices Nacionales del Currículo para la educación superior inicial (Resolución No. 02/2015); b) uso de innovaciones tecnológicas; c) articulación con los coordinadores para que todos los títulos de licenciatura ofrecidos en UNESP cumplan con las Directrices curriculares complementarias para la formación de docentes de educación básica en los cursos de pregrado de pedagogía, normal y de pregrado (Deliberación CEE No. 154/2017). Se considera que la AC contribuyó a la formación de todos los actores involucrados a través de acciones pedagógicas participativas, colaborativas y de apoyo, perspectiva inclusiva, preparándolos para los desafíos presentados en el campo educativo.

PALABRAS CLAVE: Enseñanza superior. Pedagogía. Aprendizaje cooperativo.

ABSTRACT: Cooperative Learning (CL) is a teaching and learning methodology that aims to overcome the traditional through cooperative activities; still little adopted in higher education, presupposes the formation of heterogeneous groups. This manuscript aims to report the experience lived in the discipline "Teaching Practice in Early Childhood Education" of a Pedagogy undergraduate class using the CL methodology. 35 students from São Paulo State University - UNESP, Bauru/SP/Brazil enrolled in the 2nd year participated. The procedures required: $C L$ alignment; training and self-appointment of work teams; blog and logo creation; routine definition of classes; formative assessment. Each work team was provided with a notebook. The activities developed through the CL promoted: a) teacher education as recommended in the National Curriculum Guidelines for initial higher education (Resolution No. 02/2015); b) use of technological innovations; c) articulation with the coordinators so that all Bachelor Degrees offered at UNESP complied with the Complementary Curriculum Guidelines for the Training of Teachers for Basic Education in the Undergraduate Pedagogy, Normal and Undergraduate Courses (CEE Deliberation No. 154/2017). It is considered that the CL contributed to the formation of all actors involved through participatory, collaborative and supportive pedagogical actions - inclusive perspective -, preparing them for the challenges presented in the educational field.

KEYWORDS: University education. Pedagogy. Cooperative learning.

\section{Introdução}

Este manuscrito retrata a Aprendizagem Cooperativa (AC) no Ensino Superior, tendo como prerrogativa que "narrar o vivido envolve rever concepções e práticas e o resgate de trajetórias pessoais e profissionais, o que se mostra fundamental para a formação profissional das professoras e dos pesquisadores" (FERNANDES; PRADO, 2008, p. 6). 
A AC caracteriza-se pelo uso de atividades cooperativas em grupos heterogêneos, consubstanciando-se numa alternativa de superação da metodologia tradicional, que nivela os alunos e homogeneíza o ensino. Segundo Pujólas (2003), esse tipo de trabalho em grupo se apresenta como um recurso para atender a diversidade e possibilitar a aprendizagem dos diferentes alunos, pois tem como princípio a inclusão de todos considerando a singularidade de cada um.

Pesquisadores como Stendler, Damrin e Haines (1951) relatam maior eficácia do trabalho cooperativo em relação ao individual, demonstrando inclusive efeitos positivos na conduta social dos indivíduos gerados pela cooperação (LOPES; SILVA, 2009).

Nessa perspectiva, os pesquisadores Johnson, Johnson e Smith (1998) abordam a teoria da interdependência social afirmando a cooperação enquanto interdependência positiva que "resulta em interação promotora visto que os indivíduos estimulam e facilitam os esforços mútuos para se aprender" (p. 4) e complementam:

Jean Piaget ensinou que, quando os indivíduos cooperam quanto ao ambiente, um conflito sócio-cognitivo saudável ocorre, o qual cria um desequilíbrio cognitivo que, por sua vez, estimula a habilidade para se posicionar em perspectiva bem como estimula o desenvolvimento cognitivo. Lev Vygostsky acreditava que os esforços cooperativos para se aprender, entender e resolver problemas são essenciais para construir o conhecimento e transformar perspectivas conjuntas em funcionamento mental interno. Para ambos, Piaget e Vygotsky, trabalhar de modo cooperativo com parceiros e instrutores mais capazes resulta em desenvolvimento cognitivo e em crescimento intelectual (JOHNSON; JOHNSON; SMITH, 1998, p. 4).

Aplicações menos sistemáticas e menções aos conceitos de cooperação já existiam, segundo Lopes e Silva (2009), desde o século II a.C. É possível localizar princípios da AC no livro do Eclesiastes na Bíblia e no Talude (compilação da Torá), assim como nos diferentes períodos da história com pensadores, filósofos e escritores como Sócrates, Quintiliano, Séneca, Comenius e os artesãos da Idade Média, que se utilizavam da colaboração no processo de ensino-aprendizagem em seus ensinamentos e consideravam-na importante.

A AC teve sua difusão em diferentes países de diversas formas. Na Inglaterra, os pedagogos Andrew Bell (1753) e Joseph Lancaster (1778), publicaram no século XVIII obras enaltecendo o que foi chamado de Método de Ensino Recíproco ou Mútuo. Nos Estados Unidos foi fundada a primeira escola Lancasteriana no início do século XIX, difundindo a AC no continente americano. Em Portugal foi dentro das escolas militares, com objetivo de alfabetizar os soldados, que essa proposta se espalhou e acabou sendo transformada em Método de Ensino Mútuo por João Crisóstomo de Couto e Melo (LOPES; SILVA, 2009). 
O filósofo e pedagogo norte americano John Dewey destacou, no final do século XIX, a importância social da $\mathrm{AC}$, haja vista que oferece a formação de hábitos e habilidades necessárias para além da vida escolar. Contudo, foi Willian Heard Kilpatrick, unindo os princípios da $\mathrm{AC}$ e da Pedagogia de Projetos, quem difundiu essas ideias, reforçando a necessidade de o aluno aprender a viver em sociedade (BIN, 2012; KNOLL, 1996; 1997).

Todavia, o uso da $\mathrm{AC}$ declinou e perdeu espaço para metodologias competitivas e individualistas como consequência da grave crise econômica da década de 1930. Diversos interesses comerciais começaram a surgir e influenciaram no uso de técnicas competitivas, quase que totalmente, formando-se até uma Liga da Liberdade para vender competição interpessoal entre os educadores (LOPES; SILVA, 2009).

$\mathrm{O}$ método da $\mathrm{AC}$ e suas técnicas foram perdendo espaço para a metodologia competitiva, que passou a ser incorporada na formação de professores de modo que, atualmente, ocupa até $95 \%$ do tempo nas escolas norte-americanas, conforme destacam Lopes e Silva (2009) baseando-se nos trabalhos de Morton Deutch, Muzafer Sherif e Stuart Cook, da década de 1960.

Apesar disso, alguns pensadores continuaram publicando seus trabalhos com foco na AC e, em meados da década de 1970, o interesse por essa metodologia voltou a crescer. O que não é estranho, pois

[...] a capacidade para trabalhar cooperativamente tornou-se um dos fatores que mais contribuíram para a sobrevivência da nossa espécie. Ao longo da história humana, os indivíduos que organizavam e coordenavam os seus esforços para alcançar uma meta comum, foram os que tiveram maior êxito em praticamente toda a empresa humana (JOHNSON; JOHNSON, 1990, p. 23).

Há duas grandes linhas de pensamento da AC na Europa: 1) a aprendizagem para cooperar como uma meta educativa, e; 2) a aprendizagem por meio da cooperação. Na primeira linha, se põe ênfase especial no treino de competências sociais como a cognição social (LIESHOUT, 1977 apud OVEJERO, 1990), a qual atinge mais a Grã-Bretanha. Na segunda, a ênfase está na relação entre cooperação e inteligência, especialmente por parte da chamada Escola de Genebra.

De acordo com Slavin (1995), na Alemanha foi inaugurada a JenaPlan, escola que organizava os estudantes em grupos de estudo, idealizada por Peter Peterson. Na França, estudiosos como Roger Cousinet, Antonio Sérgio, M. Profit e Célestien Freinet utilizaram-se da metodologia cooperativa contribuindo para o surgimento das Cooperativas Escolares, que visavam unir a escola com a vida social. 
Segundo Slavin (1995), atualmente os Estados Unidos é o país onde mais se está implementando a AC com Johnson e Johnson (1990), Sharan e Sharan (1992), dentre outros, seguido de diferentes países do mundo com destaque para Israel, Canadá e Austrália. O autor afirma que a $\mathrm{AC}$ oferece muitos benefícios com relação às metodologias vigentes, entre elas o aumento do sucesso acadêmico dos alunos, a melhora de suas relações interpessoais e de sua autoestima, além de uma melhor aceitação de alunos com dificuldades de aprendizagem pelo restante da turma.

Então, por que será que as escolas, sobretudo as brasileiras, continuam com práticas pedagógicas que não valorizam a cooperação? Por que os professores de educação especial não trabalham colaborativamente com os professores da classe comum? Para além dessas questões, por que nos cursos de formação de professores, quase sempre tradicionais, os estudantes (com raras exceções) permanecem enfileirados, "boca de um aluno na nuca do outro", com metodologias centradas exclusivamente no professor?

É notável que não podemos atuar desvinculados dos demais colegas de outras áreas do currículo, para não incorrer em continuar reproduzindo um modelo clínico de atendimento educacional especializado aos estudantes público-alvo da educação especial ${ }^{4}$ (BRASIL, 2008), só que agora na escola comum, não garantindo, de fato, a escolarização de todos os estudantes, sobretudo daqueles que necessitam de adequações curriculares nos conteúdos, ou seja, para além das metodologias e dos recursos, em função de sérios comprometimentos que algumas deficiências impõem.

Nesse sentido entendemos a relação entre AC e Educação Especial numa perspectiva de Educação Inclusiva, conforme Pujólas (2003), que apresenta a AC como filosofia para uma aula inclusiva, ou seja:

'Filosofía' del aula inclusiva: Se trata de sensibilizar al alumnado y hacer crecer en él la vivencia de los valores implícitos a la inclusión así como la satisfacción por vivir estos valores. Se trata de trabajar con los alumnos "lemas" parecidos a los siguientes: Todos aprendemos de todos". "Aquí cabe todo el mundo" "Tengo derecho a aprender de acuerdo con mi capacidad. Esto quiere decir que nadie. Puede poner me un mote por mi forma de aprender". "Tengo derecho a ser yo mismo. Nadie puede tratarme de forma injusta debido al color de mi piel, a mi peso, a mi estatura, por el hecho de ser niño o niña, ni debido a mi aspecto" (PUJÓLAS, 2003, p. 6).

${ }^{4}$ Art. 58 - Entende-se por educação especial, para os efeitos desta Lei, a modalidade de educação escolar oferecida preferencialmente na rede regular de ensino, para educandos com deficiência, transtornos globais do desenvolvimento e altas habilidades ou superdotação. Redação dada pela Lei n ${ }^{\circ}$ 12.796, de 2013. Disponível em: http://www.planalto.gov.br/ccivil_03/_Ato2011-2014/2013/Lei/L12796.htm\#art1. Acesso em: jul. 2016. 
A colaboração é e sempre foi muito relevante como estratégia do ensino colaborativo/coensino - uma estratégia de atuação pedagógica em educação especial no qual um educador comum e um educador especial dividem a responsabilidade de planejar, ensinar e avaliar um grupo heterogêneo de estudantes, de modo a favorecer a aprendizagem de todos os estudantes (CAPELLINI, 2004). Assim, a AC enquanto metodologia de ensino para a classe comum pode se tornar uma possibilidade, na qual as diferenças são valorizadas e todos podem aprender.

Segundo Pujólas (2003), a AC, além de método, deve ser um conteúdo aprendido pelos estudantes. Ademais, fomenta uma escola inclusiva, pois as tarefas realizadas pelos alunos se adequam às suas capacidades; as tarefas são variadas e requerem níveis e habilidades diversos para que todos possam participar; as atividades são planejadas de modo que todos participem, ou seja, a atividade não termina sem que todos tenham terminado sua parte; o apoio dos pares é fundamental.

Esta perspectiva coaduna com os pressupostos de Booth e Ainscow (2012), quando afirmam que a inclusão escolar implica reestruturar a cultura, as políticas e as práticas educacionais, para que possam atender à diversidade dos alunos, isto é, a inclusão se refere à aprendizagem e à participação de todos os estudantes vulneráveis que se encontram sujeitos à exclusão, não somente aqueles com deficiência ou rotulados como apresentando necessidades educacionais especiais, como também aqueles que, por apresentarem grandes dificuldades na aprendizagem, são colocados à margem.

Vivemos um novo paradigma em que o antigo modelo de escola, com sua estrutura e organização conservadoras não atende à demanda da contemporaneidade. Portanto, acreditamos que a inclusão escolar visa à melhoria das escolas, tanto em relação ao corpo docente como aos estudantes.

Nesta perspectiva questionamos: o currículo sem adaptação alguma pode ser acessado por todos os estudantes, mesmo aqueles com deficiências mais acentuadas? As escolas devem flexibilizar, adequar, adaptar o currículo? Como operacionalizar o que grandes pesquisadores como Célestien Freinet, Jean Piaget, John Dewey, Lev Vygotsky, entre outros já demonstraram, ou seja, o que de fato fazer para romper com modelos de escola que não atendem a heterogeneidade e quais práticas pedagógicas que valorizem a singularidade podemos implementar? Não aspiramos responder a essas perguntas, mas foram elas que embasaram a experiência aqui relatada.

Considerando que um dos fatores que tem impactado negativamente a formação dos professores é a dissociação entre a teoria e a prática e, muitas vezes, a ausência de 
organização do trabalho pedagógico, acreditamos que se faz necessário inovar em nossas práticas de formação de professores, ou seja, romper com as práticas diretivas, conteudistas, individuais e com o currículo organizado disciplinarmente, almejando que os futuros professores atuem de forma a valorizar a autonomia, a participação, a colaboração de seus alunos e também entre seus pares.

É neste sentido que a formação de professores baseada na $\mathrm{AC}$ se faz relevante e, ao mesmo tempo, inovadora, haja vista tratar-se de uma prática ainda pouco adotada pelos docentes.

Assim, este manuscrito almeja relatar a experiência vivenciada ao desenvolver o plano de ensino da disciplina Prática de Ensino na Educação Infantil de uma turma de licenciatura em Pedagogia utilizando a metodologia de AC.

\section{Desenvolvimento}

A experiência aqui relatada ocorreu no $2^{\circ}$ semestre de 2015 na turma do $2^{\circ}$ ano da Licenciatura em Pedagogia (período noturno) na Universidade Estadual Paulista UNESP/Bauru durante a realização da disciplina "Prática de Ensino na Educação Infantil". Na ocasião, todos os 35 alunos da turma foram envolvidos num trabalho coordenado pela docente responsável pela disciplina (primeira autora deste manuscrito) e pela aluna de mestrado que atuou como estagiária em docência no ensino superior (segunda autora deste manuscrito). Os conteúdos trabalhados foram:

\section{O processo ensino-aprendizagem na Educação Infantil}

- A construção do conhecimento na primeira infância.

- A interação no desenvolvimento da criança.

- Interações criança-criança, interações adultos-crianças e interações adulto-adulto em creche e pré-escola.

- A importância do brincar no desenvolvimento infantil e como eixo de propostas pedagógicas.

\section{Organização, Planejamento e Gestão do Trabalho Docente na Educação Infantil}

- Organização de ambientes que promovam o desenvolvimento da criança e o conhecimento de si e do mundo.

- Rotina em instituições de educação e cuidado coletivos. 
- Processos e projetos de Adaptação em creche e pré-escola.

- Propostas pedagógicas para instituições de educação infantil: High/Scope, Ecológica, Reggio Emília, Associação Criança.

- Referências Curriculares para a Educação Infantil e outras propostas brasileiras.

- Saúde e nutrição em creche.

- Formação do profissional de educação infantil.

\section{Articulação da Prática Pedagógica com os eixos norteadores do currículo, temas} geradores, disciplinas e atividades didáticas.

- Prática Pedagógica e Desenvolvimento Humano.

- Prática Pedagógica, Educação e Sociedade.

- Prática Pedagógica e a relação com Educação e Comunicação.

- Prática Pedagógica e o Saber Escolar.

\section{Leitura do livro "Criança que brinca mais aprende mais: a importância da atividade lúdica para o desenvolvimento cognitivo infantil" 5.}

A adoção da $\mathrm{AC}$ na abordagem desses conteúdos primou pela cooperação em detrimento da competição, bem como o respeito e valorização do outro, uma vez que, nessa perspectiva, um aprende com o outro e, como todos precisam participar, aprendem que a equipe se fortalece e atinge os objetivos se todos se desenvolverem.

O trabalho foi iniciado acordando com todos os graduandos a proposta da nova metodologia, subsidiada pela leitura e roda de conversa do texto "El aprendizaje cooperativo: algunas ideas practicas" (PUJÓLAS, 2003). Também foi disponibilizado como leitura complementar para apropriação da proposta o texto “Aprendizaje Cooperativo: Guías rápidas para nuevas metodologias" (UNIVERSIDAD POLITECNICA DE MADRID - UPM, 2008).

A turma se dividiu em seis equipes de trabalho que foram por elas denominadas como: Enxame de Ideias, Eu Passarinho, Colcha Pedagógica, Turma Pé na Estrada, Educando e Mão na Massa. Sugeriu-se que criassem um $b \log ^{6}$ ilustrado por uma $\operatorname{logo}$ definindo a equipe, para tanto, foi disponibilizado um notebook a cada equipe para utilização durante o transcorrer da disciplina.

5 POZAS, D. Criança que brinca mais aprende mais: a importância da atividade lúdica para o desenvolvimento cognitivo infantil. Rio de Janeiro: Editora SENAC, 2012.

${ }^{6}$ Trata-se de uma página na internet que é apresentada cronologicamente e em parágrafos. Os blogs de cada equipe foram vinculados ao blog da docente, como pode ser observado em: http://aprendizagemcooperativaveracapellini.blogspot.com/?m=0. Acesso em: jan. 2018. 
A escolha do nome da equipe retratou a motivação de cada equipe durante seu processo de formação inicial na Pedagogia, como exemplo apresentamos o texto da equipe "Eu passarinho", disponibilizado em seu blog:

Em 1978 a Academia Brasileira de Letras, pela terceira vez, negou a Mario Quintana uma cadeira na instituição. Quintana, poeta e escritor gaúcho, escreveu em resposta um de seus mais conhecidos poemas, o "Poeminha do Contra":

\section{"Todos esses que aí estão Atravancando meu caminho, Eles passarão... Eu passarinho!"}

A $\operatorname{logo}$ criada por cada equipe retrata o processo de formação no ensino superior, como podemos observar na Figura 1.

Figura 1 - logo da equipe "Colcha pedagógica".

Fonte: Blog da equipe "Colcha Pedagógica"

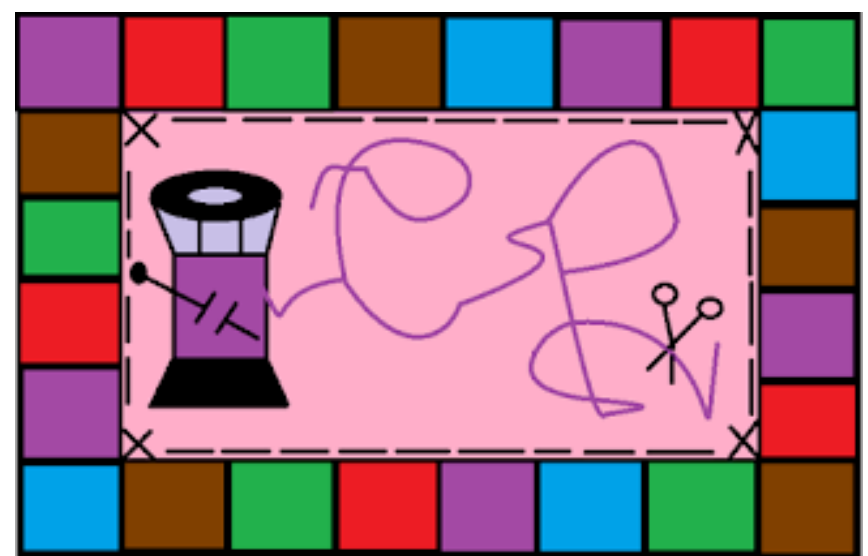

A rotina dos dias de trabalho envolveu: 1) cantar; 2) ler ou declamar uma poesia; 3) elaborar o plano de equipe para aquele dia de trabalho conforme atividade proposta pela docente; 4) desenvolver o plano de trabalho; 5) produzir narrativas sobre as suas próprias memórias, relacionadas com a(s) atividade(s) do dia.

O cantar foi estabelecido com base no texto "Formação Inicial de Professores para a Educação Básica: uma (re)visão radical” (MELLO, 2000), que explica:

A situação de formação profissional do professor é invertidamente simétrica à situação de seu exercício profissional. Quando se prepara para ser professor ele vive o papel de aluno. O mesmo papel, com as devidas diferenças etárias, que seu aluno viverá tendo a ele como professor. Por essa razão, tão simples e óbvia quanto difícil de levar às últimas conseqüências, a formação do professor precisa tomar como ponto de referência a partir do 
qual orientar a organização institucional e pedagógica dos cursos, a simetria invertida entre a situação de preparação profissional e o exercício futuro da profissão (MELLO, 2000, p. 8).

Quanto à poesia, o poeta Affonso Romano de Sant'Anna diz que ela "sensibiliza qualquer ser humano. É a fala da alma, do sentimento. E precisa ser cultivada" (s/d), algo que se pode afirmar também cientificamente, de acordo com Silva e Jesus (2011):

Os professores devem trabalhar com a poesia com seus alunos porque esta atividade vem sendo indicada como um dos meios mais eficazes para trabalhar o desenvolvimento das habilidades de percepção sensorial da criança e do adolescente, do senso estético e de suas competências leitoras e simbólicas (SILVA; JESUS, 2011, p. 32).

Consideramos tais rotinas como relevantes para a formação do professor, uma vez que ao almejar que futuramente cantem ou leiam poesias para seus alunos, é necessário que tenham aprendido como fazer isso. Afinal, "ninguém facilita o desenvolvimento daquilo que não teve oportunidade de desenvolver em si mesmo. Ninguém promove a aprendizagem de conteúdos que não domina nem a constituição de significados que não possui ou a autonomia que não teve oportunidade de construir" (MELLO, 2000, p. 9).

Conforme apontam Elbaz-Luwish (2002) e Souza (2006), a produção de narrativas e os métodos biográficos na formação de professores têm sido utilizados de forma crescente. Nos últimos anos, a narrativa tem se constituído num espaço de formação profissional, pois, na forma escrita ou oral, o sujeito se revela ao expressar seus sentimentos, suas verdades, seus pensamentos sobre si e sobre a profissão escolhida.

O Quadro 1 apresenta exemplos de atividades desenvolvidas na disciplina.

Quadro 1 - Exemplos de atividades desenvolvidas na disciplina.

\begin{tabular}{|c|c|c|}
\hline Canção & Terezinha de Jesus & Cantada e dançada por toda a sala, inclusive a docente e estagiária. \\
\hline Poesia & $\begin{array}{l}\text { Mãos Dadas (Poema } \\
\text { da obra Sentimento do } \\
\text { mundo) }\end{array}$ & $\begin{array}{l}\text { Não serei o poeta de um mundo caduco. } \\
\text { Também não cantarei o mundo futuro. } \\
\text { Estou preso à vida e olho meus companheiros. } \\
\text { Estão taciturnos mas nutrem grandes esperanças. } \\
\text { Entre eles, considero a enorme realidade. } \\
\text { O presente é tão grande, não nos afastemos. } \\
\text { Não nos afastemos muito, vamos de mãos dadas. } \\
\text { Não serei o cantor de uma mulher, de uma história, } \\
\text { não direi os suspiros ao anoitecer, a paisagem vista da janela, } \\
\text { não distribuirei entorpecentes ou cartas de suicida, } \\
\text { não fugirei para as ilhas nem serei raptado por serafins. } \\
\text { O tempo é a minha matéria, do tempo presente, os homens } \\
\text { presentes, a vida presente. } \\
\text { (Carlos Drummond de Andrade) }\end{array}$ \\
\hline
\end{tabular}

RIAEE - Revista Ibero-Americana de Estudos em Educação, Araraquara, v. 15, n. esp. 2, p. 1685-1701, ago. 2020. e-ISSN: 1982-5587. 


\begin{tabular}{|c|c|c|}
\hline Leitura & $\begin{array}{l}\text { Parte III - Ambientes } \\
\text { facilitadores. }\end{array}$ & $\begin{array}{l}\text { MOYLES, J. R. et al. Fundamentos da educação infantil: } \\
\text { enfrentando o desafio. Porto Alegre: Artmed, } 2010 \text {. }\end{array}$ \\
\hline Filme & $\begin{array}{l}\text { Educação: a } \\
\text { importância dos } \\
\text { estímulos na primeira } \\
\text { infância }\end{array}$ & https://youtu.be/0EMFNPHwRbU \\
\hline $\begin{array}{l}\text { Produção de } \\
\text { um texto } \\
\text { coletivo em } \\
\text { equipe } \\
\text { acerca dos } \\
\text { que os } \\
\text { professores } \\
\text { devem } \\
\text { considerar } \\
\text { para } \\
\text { organizar o } \\
\text { trabalho na } \\
\text { educação } \\
\text { infantil. }\end{array}$ & $\begin{array}{l}\text { Aula do dia } 07 \text { de mai } \\
\text { Construção de texto } \\
\text { relacionando-as com o } \\
\text { Para a confecção do } \\
\text { portanto iniciaremos c } \\
\text { setembro de } 1967 \text {, em } \\
\text { marcado pela força da } \\
\text { Dessa época, recorda- } \\
\text { espaços para brincad } \\
\text { entusiasmo). Também } \\
\text { momento militar. Con } \\
\text { regulações claras, que } \\
\text { sexo feminino, e nen } \\
\text { quando não se realizav } \\
\text { Pé na Estrada 2, nasc } \\
\text { municipais e particula } \\
\text { a terra e os parquinho } \\
\text { construtivismo, em q } \\
\text { painéis. A água e a } \\
\text { aventura, descoberta, } \\
\text { Pé na Estrada } 3 \text { nasc } \\
\text { em } 1997 \text {, aos } 4 \text { anos } \\
\text { confecção das cortina } \\
\text { professora Márcia os } \\
\text { brincadeiras. Era a ale } \\
\text { que aconteciam anual } \\
\text { aprendizado dos aluno } \\
\text { Pé na Estrada } 4 \text {, nasci } \\
1999 \text { em escola públic } \\
\text { dupla, pinturas a ded } \\
\text { com os alunos, em que } \\
\text { Pé na Estrada } 5 \text {, nas } \\
\text { Estudou na escola ma } \\
\text { possuía muito espaço } \\
\text { de salas, lembra-se de } \\
\text { havia um pequeno jar } \\
\text { bem diferentes umas } \\
\text { “quando um burro fale } \\
\text { alunos, que os ensinou } \\
\text { Notamos que o que m } \\
\text { e emoções. Emoções, } \\
\text { de formação, o que t } \\
\text { especial” de Aamir Kl } \\
\text { em nossa realidade, a } \\
\text { desses professores est } \\
\text { sinceras de criança. Ca } \\
\text { anos iniciais onde con }\end{array}$ & 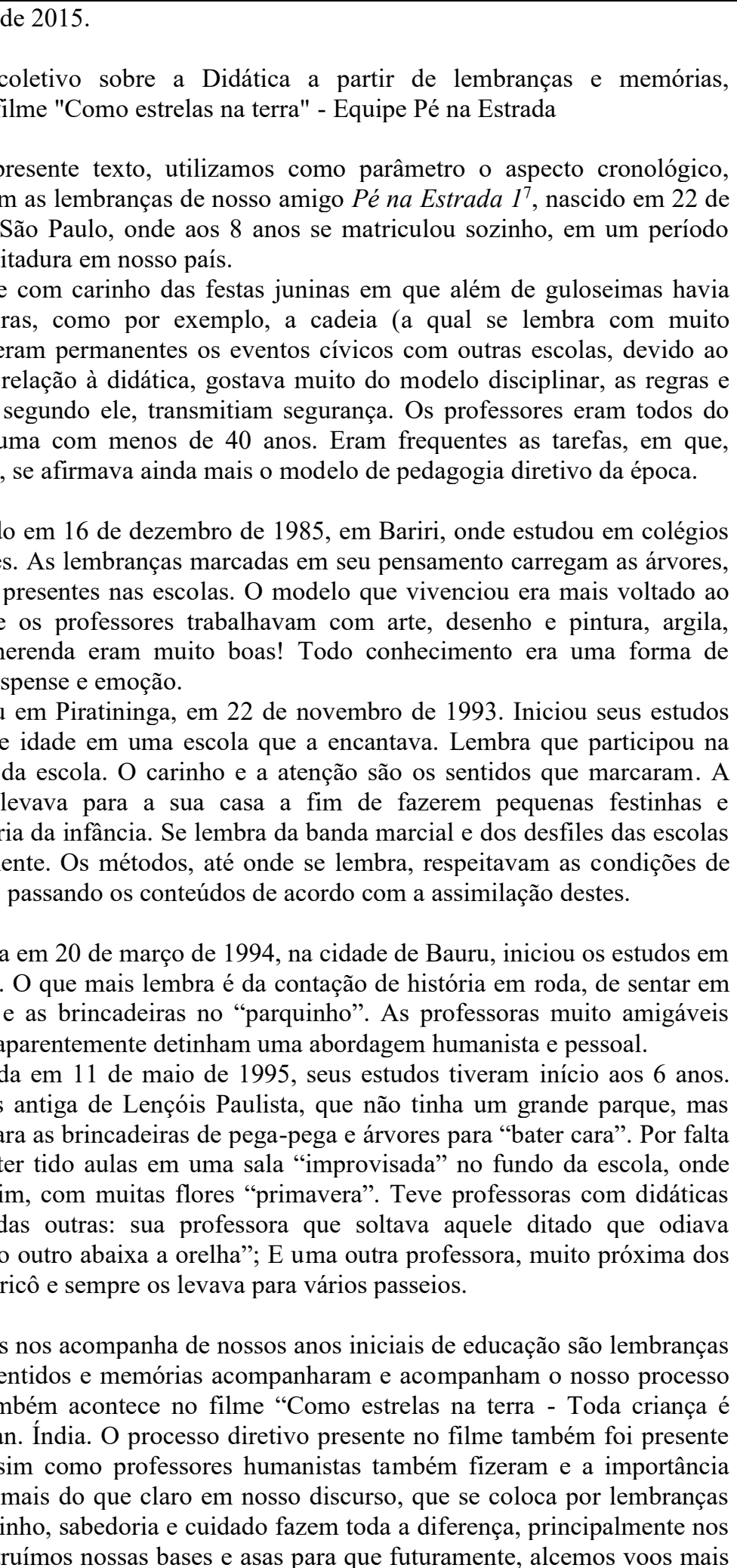 \\
\hline
\end{tabular}

${ }^{7}$ Mesmo o material sendo público no blog, optamos em substituir os nomes dos graduandos. 


\begin{tabular}{|l|l|}
\hline & alto \\
\hline
\end{tabular}

Fonte: Elaborado pelas autoras com base no material disponibilizado no Blog. Disponível em: http://aprendizagemcooperativaveracapellini.blogspot.com/?m=0. Acesso em: jan. 2018.

Para avaliação formativa os seguintes aspectos foram contemplados:

- autoavaliação - característica importante da AC - de cada Plano de Equipe, ou seja, semanal;

- avaliação pelos pares da equipe e pela docente, gerando um rol quanti e qualitativo que, por meio de uma média e dos vários feedbacks, possibilitou a cada aluno uma análise crítica, reflexiva e formativa;

- feedback da docente de todas as atividades realizadas/produzidas pelas equipes de trabalho, possibilitando aos alunos reconhecerem os objetivos atingidas durante o processo de aprendizagem e aqueles que careciam de apropriação;

- prova em dupla sobre o livro recomendado - constou de desafio na elaboração de uma proposição de organização do trabalho pedagógico na educação infantil, considerando a leitura do livro e uma atividade prática realizada em escola de educação infantil;

- prova individual - contendo questões discursivas e principalmente objetivas, uma vez que ao concluírem a graduação os alunos se deparam com concursos, ocasião em que a experiência com uma avaliação objetiva terá sido relevante. Ademais, para a AC, a avaliação individual é uma forma de promover a responsabilidade.

A Figura 2 mostra um exemplo de autoavaliação dos alunos da equipe "Mão na Massa", sendo que seus nomes foram ocultados. É possível observar que a autoavaliação foi crítica, desconstruindo o mito que o aluno ao se autoavaliar lhe atribuirá nota máxima, mesmo sem atingir os critérios para tal.

Figura 2 - Autoavaliação dos alunos da equipe "Mão na Massa"

\begin{tabular}{|l|c|c|c|}
\hline $\begin{array}{l}\text { Auto Avaliação } \\
\text { Equipe: Măo na } \\
\text { Massa. }\end{array}$ & & & \\
\hline Trabalho TGD & 9 & 9 & 9 \\
\hline $\begin{array}{l}\text { Fichamento Livro } \\
\text { Rosita. }\end{array}$ & 7 & 8 & 8 \\
\hline Análise do Filme & 8 & 7 & 7 \\
\hline $\begin{array}{l}\text { Perguntas } \\
\text { (Sexualidade) }\end{array}$ & 10 & 10 & 10 \\
\hline \multicolumn{1}{|c|}{ Média } & 8,5 & 8,5 & 8,5 \\
\hline
\end{tabular}

Fonte: Blog da equipe "Mão na Massa" 
Dessa forma, todas as atividades avaliativas foram igualmente consideradas, fato que possibilita a minimização do estresse nos alunos como é comum ao realizarem somente provas individuais.

Com base nas atividades desenvolvidas na disciplina durante um semestre letivo, podemos inferir que a $\mathrm{AC}$ promove a formação docente, conforme preconizado no $\S 3^{\mathrm{o}}$ do Art. $3^{\circ}$ da Resolução $\mathrm{n}^{\mathrm{o}} 2$, de $1^{\mathrm{o}}$ de julho de 2015, que define as Diretrizes Curriculares Nacionais para a formação inicial em nível superior, pois busca a "[...] formação dos profissionais do magistério [...] que promova a emancipação dos indivíduos e grupos sociais, atenta ao reconhecimento e à valorização da diversidade e, portanto, contrária a toda forma de discriminação".

Além disso, no Art. $5^{\circ}$ item IV, a Resolução destaca que a formação de profissionais do ensino superior deve abarcar: "dinâmicas pedagógicas que contribuam para o exercício profissional [...] possibilitando as condições para o exercício do pensamento crítico, a resolução de problemas, o trabalho coletivo e interdisciplinar, a criatividade, a inovação, a liderança e a autonomia"; e no item VI, o "uso competente das Tecnologias de Informação e Comunicação (TIC) para o aprimoramento da prática pedagógica e a ampliação da formação cultural dos(das) professores(as) e estudantes".

Assim, a experiência aqui relatada nos possibilitou experenciar por meio do trabalho cooperativo alternativas pedagógicas participativas, colaborativas e solidárias, o que contribuiu para a formação inicial dos graduandos em Pedagogia e para a formação continuada da docente e estagiária do ensino superior

\section{Considerações finais}

Concernente à contribuição desta metodologia para o desenvolvimento profissional do professor de ensino superior alguns aspectos merecem destaque. $\mathrm{O}$ primeiro diz respeito à preocupação com os currículos de todos os cursos de Licenciatura da Faculdade e, neste sentido, foi enviada à direção da Faculdade proposta para criação de uma comissão de estudo sobre flexibilização curricular, que culminou na Portaria da Diretora da FC.C.BRU n ${ }^{\circ}$ 033, de 23 de março de $2016^{8}$. Essa iniciativa objetivou estudar diferentes possibilidades de currículo no ensino superior, visando aprimorar metodologias que, em sua maioria, não atendem mais a geração atual de graduandos.

${ }^{8}$ Disponível em: https://www.fc.unesp.br/Home/Administracao/secaograduacao/portaria-033-2016.pdf. Acesso em: jan. 2018. 
A prática com $\mathrm{AC}$ aqui relatada promoveu a utilização de inovações tecnológicas que passaram a contemplar a prática docente; essa integração é reconhecida pela Organisation for Economic Co-operation and Development - OCDE (2004) como necessária no currículo, pois possibilita aprendizagens, além de preparar os alunos para os desafios do século XXI. Afirmam que os professores em formação não usam as TDIC em contexto de sala de aula com a regularidade que seria desejável pedagogicamente.

Visando integrar as tecnologias nas práticas de sala de aula, faz-se necessário:

[...] dar oportunidade ao professor de se apropriar do domínio da tecnologia, ao mesmo tempo que analisa suas potencialidades e limitações e desenvolve práticas pedagógicas com o acompanhamento e orientação do grupo em formação. Assim, o professor compartilha avanços e equívocos com outros profissionais que estão passando pelas mesmas situações e recebem orientação dos formadores para superar as dificuldades e desafios decorrentes da experimentação de novas práticas (ALMEIDA, 2007, p. 160).

Outro aspecto a ser destacado foi a articulação junto aos coordenadores para que todas as Licenciaturas oferecidas na UNESP atendessem à Deliberação CEE nº 111/2012, atualizada pela Deliberação CEE $n^{0}$ 154/2017, que fixa Diretrizes Curriculares Complementares para a Formação de Docentes para a Educação Básica nos Cursos de Graduação de Pedagogia, Normal Superior e Licenciaturas, oferecidos pelos estabelecimentos de ensino superior vinculados ao sistema estadual. Tal articulação decorre da avaliação das narrativas dos graduandos que apresentaram dificuldades na produção textual (temática essa tratada e defendida na Deliberação).

Além disso, a prática com a $\mathrm{AC}$ possibilitou o reconhecimento de que docentes não podem se acomodar na sua tradicional organização do trabalho pedagógico, ainda que por vezes um ou outro aluno relate preferência por aulas expositivas e diretivas, e/ou que encontre resistências entre seus pares da docência, é preciso ter coragem de implementar novas práticas, pois se queremos uma educação básica diferente, o primeiro passo deve ser dado na Universidade, locus privilegiado da produção de novos conhecimentos.

Assim, esta proposta nos desafia a buscar coerência entre discurso e prática, além de perseguir a indissociabilidade entre teoria e prática. De acordo com o que já dizia Paulo Freire (1996, p. 34), "ensinar exige a corporeificação da palavra pelo exemplo". O professor que de fato promove a aprendizagem não aceita o "faça o que eu mando e não o que eu faço". Ele sabe que as palavras às quais falta corporeidade do exemplo quase nada valem. É preciso uma prática testemunhal que confirme o que se diz em lugar de desdizê-lo (FREIRE, 1996). 
No que se refere às contribuições do projeto para a formação dos licenciandos, destacamos que ao final da disciplina os 35 alunos foram convidados a fazer uma avaliação da disciplina pelo googledoc. No item "relação aluno-aluno", aparece menção à AC, conforme exemplos de relatos: “[...] os alunos se ajudam [...] por ser aprendizagem cooperativa"; "Equipes trabalham de forma organizada respeitando as diferenças"; "a relação é amigável".

Com base em todas as atividades desenvolvidas na disciplina, podemos afirmar que, para os alunos, trabalhar com a $\mathrm{AC}$ significou abrir novos horizontes em relação à sua futura atuação docente, vislumbrar alternativas pedagógicas participativas, colaborativas e solidárias. A experiência da AC no seu processo de formação os despertou para a necessidade de tomar a frente da sala de aula, conduzir o seu processo de aprendizagem, descobrir caminhos para o conhecimento de forma autônoma e comprometida. Este exercício terá sido de grande importância quando, já formados, se depararem com os desafios da educação na sociedade contemporânea e todas as transformações que se apresentam no campo social, político, econômico e que, inevitavelmente, se refletem no campo educacional.

AGRADECIMENTOS: à Coordenação de Aperfeiçoamento de Pessoal de Nível Superior CAPES pelo financiamento das pesquisas desenvolvidas pela $3^{\mathrm{a}}$ autora.

\section{REFERÊNCIAS}

ALMEIDA, M. E. B. de. Tecnologias digitais na educação: o futuro é hoje. In: ENCONTRO DE EDUCAÇÃO E TECNOLOGIAS DE INFORMAÇÃO E COMUNICAÇÃO, 5., 2007, Rio de Janeiro. Anais [...]. Rio de Janeiro: Universidade Estácio de Sá, 2007. Disponível em: https://etic2008.files.wordpress.com/2008/11/pucspmariaelizabeth.pdf. Acesso em: 19 jul. 2016.

BIN, A. C. Concepções de conhecimento e currículo em W. Kilpatrick e implicações do método de projetos. 2012. 120 f. Dissertação (Mestrado em Educação) - Universidade de São Paulo, São Paulo, 2012.

BOOTH, T.; AINSCOW, M. Index para a inclusão: desenvolvendo a aprendizagem e a participação na escola. Rio de Janeiro: UFRJ-Lapeade, 2012.

BRASIL. Política Nacional de Educação Especial na Perspectiva da Educação Inclusiva. Ministério da Educação e Cultura, 2008. Disponível em:

http://peei.mec.gov.br/arquivos/politica_nacional_educacao_especial.pdf. Acesso em: 09 ago. 2016.

BRASIL. Resolução n. 2, de $1^{\circ}$ de julho de 2015. Define as Diretrizes Curriculares Nacionais para a formação inicial em nível superior (cursos de licenciatura, cursos de formação 
pedagógica para graduados e cursos de segunda licenciatura) e para a formação continuada. Diário Oficial da União, Brasília, Seção 1, p. 8-12, 2 jul. 2015.Disponível em: http://portal.mec.gov.br/docman/agosto-2017-pdf/70431-res-cne-cp-002-03072015-pdf/file. Acesso em: 09 set. 2019.

CAPELLINI, V. L. M. F. Avaliação das possibilidades do ensino colaborativo no processo de inclusão escolar do aluno com deficiência mental. 2004. 302 f. Tese (Doutorado em Educação Especial) - Universidade Federal de São Carlos, São Carlos, 2004.

ELBAZ-LUWISCH, F. O ensino e a identidade narrativa. Revista de Educação, Lisboa, v. 11, n. 2, p. 21-33, 2002.

FERNANDES, C. H.; PRADO, G. V. T. A narrativa na formação de professoras e de pesquisadores da/na escola: diários de viagem. Educação Unisinos/RS, v. 12, n. 1, p. 5-15, jan./abr. 2008.

FREIRE, P. Pedagogia da autonomia: saberes necessários à prática educativa. São Paulo: Paz e Terra, 1996.

JOHNSON, D. W.; JOHNSON, R. T. Cooperative learning and achievement. In: SHARAN, S. (Ed.). Cooperative learning: theory and research. New York: Praeger. 1990. p. 23-37.

JOHNSON, D. W.; JOHNSON, R. T.; SMITH, K. A. A Aprendizagem cooperativa retorna às faculdades: qual é a evidência de que funciona? Change, v. 30, 1998. Disponível em: file://C:/Users/User/Downloads/a $\% 20$ aprendizagem $\% 20$ cooperativa $\% 20$ retorna $\% 20 \mathrm{~s} \% 20$ facul dades1\%20(1).pdf. Acesso em: 13 ago. 2016.

KNOLL, M. Faking a dissertation: Ellsworth Collings, William H. Kilpatrick and the "project curriculum". Journal of Curriculum Studies, v. 28, n. 2, p. 193-222, 1996.

LOPES, J.; SILVA, H. S. A aprendizagem cooperativa na sala de aula: um guia prático para o professor. Lisboa (Portugal): Lidel, 2009.

MELLO, G. N de. Formação inicial de professores para a educação básica: uma (re)visão radical. São Paulo em Perspectiva, v. 14, n. 1, p. 98-110, 2000. Disponível em: http://www.crmariocovas.sp.gov.br/pdf/Formacao_inicial_professores.pdf. Acesso em: 20 jul. 2016.

OCDE. Educationat a Glance. 2004. Disponível em:

http://www.oecd.org/document/7/0,3746,en_2649_39263238_33712135_1_1_1_1,00.html. Acesso em: 03 ago 2016.

OVEJERO, A. EI aprendizaje cooperativo: una alternativa a la enseñanza tradicional. Barcelona: P.P.U. 1990.

PUJÓLAS, M. P. El aprendizaje cooperativo: algunas ideas practicas. Universidad de Vic, nov. 2003. Disponível em:

http://www.deciencias.net/convivir/1.documentacion/D.cooperativo/AC_Algunasideaspractic as_Pujolas_21p.pdf. Acesso em: 09 jul. 2016. 
SHARAN, Y.; SHARAN, S. Expanding cooperative learning through group

investigation. New York: teachers College Press, 1992.

SILVA, E. F da; JESUS, W. G. Como e por que trabalhar com poesia na sala de aula. Revista Graduando, n. 2, p. 21-34, 2011. Disponível em:

http://www2.uefs.br/dla/graduando/n2/n2.21-34.pdf. Acesso em: 15 jul. 2016.

SLAVIN, R. E. Cooperative learning: theory, reserch, and practice. Massachusetts: Allyn and Bacon, 1995.

SOUZA, E. C. de. Pesquisa narrativa e escrita (auto) biográfica: interfaces metodológicas e formativas. In: SOUZA, E. C. de; ABRAHÃO, M. H. M. B. (Orgs.). Tempos, narrativas e ficções: a invenção de si. POA: EDIPUCRS, 2006.

STENDLER, C.; DAMRIN, D.; HAINES, A. D. Studies in cooperation and competition. I. The effects of working for group and individual rewards on the social climate of children's groups. J Genet Psychol, b1951.

UNIVERSIDAD POLITECNICA DE MADRID - UPM. Aprendizaje cooperativo: guías rápidas para nuevas metodologias. Servicio de innovacion educativa de la Universidad de Madrid, 2008. Disponível em:

http://innovacioneducativa.upm.es/guias/Aprendizaje_coop.pdf. Acesso em: 08 ago. 2016.

\section{Como referenciar este artigo}

CAPELLINI, V. L. M. F.; BELLO, M. M. S.; REIS, V. L. dos. Aprendizagem cooperativa no ensino superior: relato de uma experiência. Revista Ibero-Americana de Estudos em Educação, Araraquara, v. 15, n. esp. 2, p. 1685-1701, ago. 2020. e-ISSN: 1982-5587. DOI: https://doi.org/10.21723/riaee.v15iesp2.13839

Submetido em: 30/08/2019

Revisões requeridas: $30 / 11 / 2019$

Aprovado em: 02/02/2020

Publicado em: 01/08/2020 